\title{
ARTICLE
}

Translational Therapeutics

\section{TAS-116 inhibits oncogenic KIT signalling on the Golgi in both imatinib-naïve and imatinib-resistant gastrointestinal stromal tumours}

\author{
Yurina Saito ${ }^{1}$, Tsuyoshi Takahashi ${ }^{1}$, Yuuki Obata ${ }^{2}$, Toshirou Nishida ${ }^{2}$, Shuichi Ohkubo ${ }^{3}$, Fumio Nakagawa ${ }^{3}$, Satoshi Serada ${ }^{4}$, \\ Minoru Fujimoto ${ }^{4}$, Tomoharu Ohkawara ${ }^{4}$, Takahiko Nishigaki ${ }^{1}$, Takahito Sugase ${ }^{1}$, Masahiro Koh ${ }^{1}$, Tomo Ishida ${ }^{1}$, Koji Tanaka ${ }^{1}$, \\ Yasuhiro Miyazaki ${ }^{1}$, Tomoki Makino ${ }^{1}$, Yukinori Kurokawa ${ }^{1}$, Kiyokazu Nakajimaa ${ }^{1}$, Makoto Yamasaki ${ }^{1}$, Seiichi Hirota ${ }^{5}$, Tetsuji Naka ${ }^{4}$, \\ Masaki Mori ${ }^{1}$ and Yuichiro Doki ${ }^{1}$
}

BACKGROUND: Despite the effectiveness of imatinib mesylate (IM), most gastrointestinal stromal tumours (GISTs) develop IM resistance, mainly due to the additional kinase-domain mutations accompanied by concomitant reactivation of KIT tyrosine kinase. Heat-shock protein 90 (HSP90) is one of the chaperone molecules required for appropriate folding of proteins such as KIT. METHODS: We used a novel HSP90 inhibitor, TAS-116, which showed specific binding to HSP90a/ $\beta$ with low toxicity in animal models. The efficacy and mechanism of TAS-116 against IM-resistant GIST were evaluated by using IM-naïve and IM-resistant GIST cell lines. We also evaluated the effects of TAS-116 on the other HSP90 client protein, EGFR, by using lung cell lines.

RESULTS: TAS-116 inhibited growth and induced apoptosis in both IM-naïve and IM-resistant GIST cell lines with KIT activation. We found KIT was activated mainly in intracellular compartments, such as trans-Golgi cisternae, and TAS-116 reduced autophosphorylated KIT in the Golgi apparatus. In IM-resistant GISTs in xenograft mouse models, TAS-116 caused tumour growth inhibition. We found that TAS-116 decreased phosphorylated EGFR levels and inhibited the growth of EGFR-mutated lung cancer cell lines.

CONCLUSION: TAS-116 may be a novel promising drug to overcome tyrosine kinase inhibitor-resistance in both GIST and EGFRmutated lung cancer.

British Journal of Cancer (2020) 122:658-667; https://doi.org/10.1038/s41416-019-0688-y

\section{BACKGROUND}

Gastrointestinal stromal tumours (GISTs) are the most common gastrointestinal mesenchymal tumours. ${ }^{1}$ Approximately $85 \%$ of advanced GISTs have activating mutations in $K I T$, whereas another $5 \%$ harbour mutations in platelet-derived growth factor receptor a (PDGFRA). ${ }^{2}$ Imatinib mesylate (IM), a selective tyrosine kinase inhibitor (TKI), has been the standard therapy for patients with advanced, inoperable GISTs, and it yields long-lasting responses in the majority of patients, with a median survival of almost 5 years. ${ }^{3,4}$ However, $20 \%$ of patients show primary resistance to IM, and half of the responding patients eventually develop secondary resistance and show progression for about 2 years. ${ }^{5-7}$ GIST patients resistant to IM are basically treated with another TKI, sunitinib malate or regorafenib, which have been reported to prolong progression-free survival for 27.3 weeks and 4.8 months, respectively. ${ }^{8,9}$ Eventually, most patients develop resistance to these drugs. Such patients can develop progressing lesions at multiple metastatic sites, and each of the metastases in a patient can have different genomic mutational resistance mechanisms. ${ }^{10-12}$ Furthermore, sensitivity to TKIs varies considerably depending on the type of secondary mutation. ${ }^{7,13}$ One of the mechanisms of acquired resistance to EGFR-targeted inhibitors in
EGFR-mutated lung cancer is the occurrence of a secondary mutation (T790M, C797S) in the kinase domain. ${ }^{14}$ Therefore, it is essential to validate novel therapeutic strategies.

Heat-shock proteins help the nascent polypeptide chain attain a functional conformation and facilitate protein stability, trafficking and the proteolytic turnover necessary for protein intracellular localisation and function. ${ }^{15}$ Heat-shock protein 90 (HSP90) regulates the conformation, function and activation of several client proteins including KIT and EGFR. ${ }^{16,17}$ Many of these functions are dysregulated in cancer; therefore, targeting HSP90 may be a novel strategy to modulate the growth of certain malignancies. ${ }^{17}$ HSP90 activity is regulated by many cofactors (co-chaperones) as well as conformational changes requiring ATP hydrolysis via the ATPase function of HSP90. ${ }^{18}$ HSP9O inhibitor molecules act by competitively blocking HSP90 enzymatic activity, resulting in the degradation of HSP90 client proteins. ${ }^{16,19,20}$ HSP9O inhibitors have been reported to have anti-tumour activity in breast and prostate cancer, multiple myeloma and melanoma models. ${ }^{21-24}$ Several HSP90 inhibitors in different malignancies are currently being studied. ${ }^{25}$ Because KIT and PDGFRA are clients for HSP90, HSP90 inhibitors induce KIT degradation and are expected to be a novel strategy for GIST treatment. ${ }^{26-28}$ In diverse

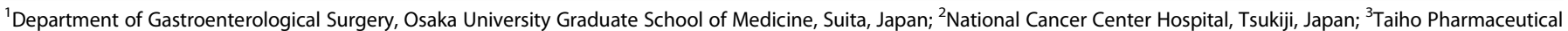
Co. Ltd, Tsukuba, Japan; ${ }^{4}$ Kochi Medical School Hospital, Nankoku, Japan and ${ }^{5}$ Department of Surgical Pathology, Hyogo College of Medicine, Nishinomiya, Japan Correspondence: Tsuyoshi Takahashi (ttakahashi2@gesurg.med.osaka-u.ac.jp) 
GIST cell lines, HSP90 inhibition has been proven to efficiently kill tumour cells. ${ }^{29-31}$

The first-generation HSP90 inhibitor, 17-AAG, can cause severe hepatotoxicity. ${ }^{32}$ Neurological toxicities such as syncope and dizziness have been observed upon using the second-generation HSP90 inhibitor BIIB021. ${ }^{33}$ In clinical trials of other HSP90 inhibitors, the most commonly observed adverse events have been reversible visual disorders, which interfere with obtaining sufficient drug exposure, because of drug interruption or discontinuation or dose reduction. ${ }^{32-36}$

TAS-116 is an orally active ATP-competitive inhibitor of HSP90a and $\beta^{37}$ It shows greater specific binding to HSP90a and $\beta$ than to highly homologous HSP90 family members GRP94 and TRTP1. TAS-116 shows anti-tumour activity in multiple xenograft models; ${ }^{37}$ however, anti-tumour activity against GIST is still unclear. In addition, it shows anti-tumour activity without detectable ocular toxicities in rats unlike other HSP90 inhibitors. ${ }^{37}$ These data suggest that TAS-116 has potential for clinical use; however, the mechanism underlying TAS-116 activity is still unclear. Therefore, the aim of this study was to clarify the effectiveness and the mechanism of TAS-116 activity in both IMnaïve and IM-resistant GISTs. Furthermore, to explore the effects of TAS-116 on other cancers, we evaluated its effects on EGFRmutated lung cancer.

\section{METHODS}

Cell culture

We used the established human GIST cell line GIST-T1 (Cosmobio, Tokyo, Japan), the identity of which was confirmed by DNA fingerprinting using short tandem repeat profiling. ${ }^{38}$ This KIT exon 11 mutant cell line is characterised by a heterozygous deletion of 57 bases. $^{39}$ GIST-T1 cells were cultured in Dulbecco's modified Eagle's medium supplemented with $10 \%$ foetal bovine serum (FBS) (HyClone Laboratories, Logan, UT) and $100 \mathrm{U} / \mathrm{ml}$ penicillin and $100 \mu \mathrm{g} / \mathrm{ml}$ streptomycin (Nacalai Tesque, Kyoto, Japan) at $37^{\circ} \mathrm{C}$ in a humid atmosphere of $5 \% \mathrm{CO}_{2}$. To generate IM-resistant cell lines, GIST-T1 cells were cultured with increasing concentrations of IM. IM-resistant cell lines, R2, R8 and R9, ${ }^{40}$ were established and maintained under a constant concentration of $1 \mu \mathrm{M}$ IM. GIST48/820 cell line and GIST430/654 were kindly provided by Dr. J. Fletcher (Dana-Farber Cancer Institute, Boston, MA, USA). GIST48/820 is characterised by a KIT exon 11 (homozygous V560D) and exon 17 (heterozygous D820A) mutation. GIST430/654 is characterised by a KIT exon 11 (nearhomozygous frame deletion) and exon 13 (heterozygous V654A). GIST48/820 cells were cultured in DMEM medium supplemented with $15 \%$ FBS, $100 \mathrm{U} / \mathrm{ml}$ penicillin, $1 \%$ glutamine (Gibco, Thermo Fisher Scientific, Waltham, MA, USA), $100 \mu \mathrm{g} / \mathrm{ml}$ streptomycin at $37^{\circ} \mathrm{C}$ in a humid atmosphere of $5 \% \mathrm{CO}_{2}$. GIST430/654 cells were cultured in DMEM medium supplemented with $15 \%$ FBS, $100 \mathrm{U} / \mathrm{ml}$ penicillin, $1 \%$ glutamine, $100 \mu \mathrm{g} / \mathrm{ml}$ streptomycin and $100 \mathrm{nM}$ imatinib at $37^{\circ} \mathrm{C}$ in a humid atmosphere of $5 \% \mathrm{CO}_{2}$. NCl-H1975 cells and HCC827 cells were purchased from American Type Culture Collection (Manassas, VA). A549 were purchased form Dainippon Pharmaceutical Co. Ltd. (Osaka, Japan). Those cells were cultured in RPMI 1640 medium supplemented with $10 \%$ FBS and $100 \mathrm{U} / \mathrm{ml}$ penicillin and $100 \mu \mathrm{g} / \mathrm{ml}$ streptomycin at $37^{\circ} \mathrm{C}$ in a humid atmosphere of $5 \% \mathrm{CO}_{2}$.

Cell proliferation assay

Cells were plated in 96-well plates at a destiny of $3 \times 10^{3}$ cells per well and incubated for $24 \mathrm{~h}$. Cell proliferation was evaluated with WST-8 [2-(2-methoxy-4-nitro-phenyl)-3-(4-nitrophenyl)-5-(2,4-disulfophenyl)-2 H-tetrazolium, monosodium salt] assays (Cell Counting Kit-SF; Nacalai Tesque) at the indicated time points after treatment. The absorption of WST- 8 was measured at a wavelength of $450 \mathrm{~nm}$ with a reference wavelength of $630 \mathrm{~nm}$ by using a microplate reader (Model 680; Bio-Rad Laboratories). The growth rate was expressed as the percentage of absorbance for treated cells versus that of control cells. Experiments were performed with six replicate wells for each sample, and the data are presented as averages.

Western blotting analysis

Cell lines and tumour tissues harvested from the xenograft mouse model were lysed in RIPA buffer (10 mM Tris- $\mathrm{HCl}$ [pH 7.5], $150 \mathrm{mM}$ $\mathrm{NaCl}, 1 \%$ Nonidet P-40, $0.1 \%$ sodium deoxycholate, $0.1 \%$ sodium dodecyl sulfate (SDS), $1 \times$ phosphatase inhibitor cocktail [Nacalai Tesque] and $1 \times$ protease inhibitor cocktail [Nacalai Tesque]) followed by centrifugation at $14,000 \times g$ for $15 \mathrm{~min}$ at $4{ }^{\circ} \mathrm{C}$. The supernatants were stored at $-80^{\circ} \mathrm{C}$ until use. Protein concentrations were determined with a DC Protein Assay kit (Bio-Rad Laboratories, Hercules, CA) using bovine serum albumin (BSA) as the concentration standard. Proteins were resolved using SDSpolyacrylamide gel electrophoresis (SDS-PAGE) with gels purchased from Wako Pure Industries (Osaka, Japan) or Bio-Rad Laboratories (Hercules, CA) and subsequently transferred to polyvinylidene difluoride membranes (Millipore, Bedford, MA). The membranes were blocked with $5 \%$ skim milk in Tris-buffered saline containing $0.1 \%$ Tween 20 and incubated with the respective antibodies against different targets. The following antibodies were used: anti-phospho-c-KIT (Y703), anti-phosphoAKT (S473), anti-AKT, anti-phospho-p44/42 mitogen-activated protein kinase (MAPK) (T202/Y204), anti-p44/42 MAPK, antiphospho-EGFR (Y1068), anti-EGFR (all from Cell Signaling Technology, Danvers, MA), anti-CKIT (C-19), anti-HSP90, anti-GAPDH (all from Santa Curz Biotechnology, Dallas, TX) and anti-HSP70 antibodies (from StressGen Biotechnologies Corporation, Victoria, BC). Next, the membranes were incubated with horseradish peroxidase-conjugated sheep anti-mouse lgG, horseradish peroxidase-conjugated (HRP-conjugated) donkey anti-rabbit IgG (GE Healthcare, Little Chalfont, Buckinghamshire, UK) or HRPconjugated goat anti-rabbit IgG (Cell Signaling Technology, Danvers, MA). Finally, the signals were visualised using an enhanced chemiluminescence reaction system (Perkin-Elmer Life Sciences, Boston, MA).

Caspase-3/7 activity assay

GIST cell lines were plated into 96-well white plates at a density of $3 \times 10^{3}$ cells per well and treated with IM and TAS-116 for $24 \mathrm{~h}$. The activities of caspase- 3 and caspase-7 in cell culture were detected using Caspase Glo 3/7 Assays (Promega, Madison, WI) according to the manufacturer's instructions. Luminometer readings were determined $1 \mathrm{~h}$ after addition of the reagent by using a Spectra Max Gemini EM Microplate Reader (Molecular Devices, Sunnyvale, CA).

Immunofluorescence confocal microscopy

The following antibodies were purchased: anti-KIT (M-14) from Santa Cruz Biotechnology (Dallas, TX); anti-KIT (D13A2) and antiphospho-KIT (Y703) from Cell Signaling Technology (Danvers, MA); anti-GM130 34 from BD Transduction Laboratories (Franklin Lakes, $\mathrm{NJ}$ ) and anti-PDI from Abcam (Cambridge, UK). Alexa Fluorconjugated secondary antibodies were obtained from Molecular Probes (Eugene, OR).

Cells cultured on poly-L-lysine-coated coverslips were fixed with $4 \%$ paraformaldehyde for $20 \mathrm{~min}$ at $25^{\circ} \mathrm{C}$. The fixed cells were permeabilised and blocked for $30 \mathrm{~min}$ in PBS supplemented with $0.1 \%$ saponin and $3 \%$ BSA, and then incubated with a primary and secondary antibody for $1 \mathrm{~h}$ each. Confocal images were obtained using a Fluoview FV10i laser scanning microscope with an x60 1.20 N.A. water-immersion objective (Olympus, Tokyo, Japan). Composite figures were prepared with Photoshop Elements 10 and Illustrator CS6 software (Adobe, San Jose, CA). 
660

Analysis of protein glycosylation

Following the manufacturer's instructions (New England Biolabs, Ipswich, MA), NP-40 cell lysates were treated with endoglycosidases for $1 \mathrm{~h}$ at $37^{\circ} \mathrm{C}$. The reactions were stopped with SDS-PAGE sample buffer; the products were resolved by SDS-PAGE and immunoblotted with the anti-KIT antibody.

\section{GIST cell xenograft mouse models}

In this study, since it is essential to provide the efficacy and safety of this drug in animal model, we carried out animal experiments. All animal experiments were conducted according to the institutional ethical guidelines for animal experimentation of Taiho Pharmaceutical Co., Ltd. Mice were housed in a temperature-controlled room with $12 \mathrm{~h}$ light/ $12 \mathrm{~h}$ dark cycle and provided free access to water and diets in the laboratory of Taiho Pharmaceutical Co., Ltd. GIST T1 and R8 cells were implanted in BALB/cAJcl-nu/nu mice obtained from CLEA Japan Inc. (Tokyo, Japan), and GIST R9 cells were implanted in C.B-17/lcr-scid/scidJcl mice obtained from CLEA Japan Inc. (Tokyo, Japan). For cell inoculation, $1.0 \times 10^{7}$ cells were injected subcutaneously into the flanks of the mice. When the tumour volume reached approximately $150 \mathrm{~mm}^{3}$, the mice were randomly divided into three groups. The animals were treated orally for 3 weeks with control ( $0.5 \mathrm{w} / \mathrm{v} \%$ hydroxypropyl methyl cellulose every day), IM (50 mg/ $\mathrm{kg}$ twice daily every day) and TAS-116 (14 mg/kg once daily five times a week) at home cage. Drug dose used was determined according to the previous report. ${ }^{37}$ Tumour sizes were measured twice a week, and body weight was measured at the same time throughout the study. Tumour volumes were determined by measuring the length $(L)$ and width $(W)$ and calculated as $\left(W^{2} \times L\right)$ / 2. Tumours were resected 22 days after the first treatment. For the xenograft experiments, the mice were anaesthetised by $3 \%$ isoflurane in invasive procedure and killed by standard $\mathrm{CO}_{2}$ asphyxiation.

Immunohistochemistry

Subcutaneously implanted tumours were harvested and embedded in paraffin for immunohistochemical analysis using the CD117 polyclonal rabbit immunostain (Dako Corporation, Carpinteria, CA) and anti-Ki67 antibodies (Novocastra Laboratories, Newcastle, UK). Terminal dUTP nick-end labelling (TUNEL) assays (with DAPI Fluorescein In Situ Apoptosis Detection Kit [Chemicon International, Temecula, CA] were performed according to the manufacturer's instructions.

Statistical analysis

Data are shown as mean $\pm S D$ values for in vitro and in vivo experiments. To test for statistically significant differences between the two groups, the Tukey-Kramer honestly significant difference test was used. Differences were considered significant at $P<0.05$. All analyses were performed using JMP version 11.0 (SAS Institute, Cary, NC).

\section{RESULTS}

Inhibition of GIST cell proliferation by TAS-116 treatment

To analyse the growth inhibitory mechanism of TAS-116 in GIST cells, we used IM-naïve GIST T1 and IM-resistant GIST R8, R9, and R2. GIST R8 and R9 cells have KIT secondary mutation D820Y and D820V, respectively, whereas GIST R2 cells do not have KIT secondary mutation. The $\mathrm{IC}_{50}$ values of TAS-116 for GIST T1, R8, R9 and R2 were 284.0, 500.4, 334.9 and $731.8 \mathrm{nM}$, respectively (Fig. 1a). Figure $1 \mathrm{~b}$ shows that TAS-116 inhibited the proliferation of IM-naïve and IM-resistant GIST cell lines similarly in a dosedependent manner, whereas it inhibited the proliferation of GIST $R 2$ cells to a lesser extent, in which the growth is not dependent on KIT activation under imatinib existence (Fig. 1c). The immunoblotting analysis showed that TAS-116 treatment induced
HSP70 expression, an indicator of HSP90 inhibition, in GIST T1, R8, R9 and R2 cells. IM significantly inhibited KIT phosphorylation and the subsequent signalling pathways in the IM-naïve cell line (T1). In contrast, TAS-116 decreased total KIT, as well as phosphorylated KIT (pKIT) levels and the downstream signalling pathways, such as phosphorylated p44/42 MAPK and AKT (T1, R8 and R9). Similar findings were obtained in GIST48/820 and GIST430/654 (Supplementary Fig. 1a, b). Importantly, pKIT appeared to be more sensitive to TAS-116 and was more prominently decreased than total KIT. In contrast, although TAS-116 decreased total KIT as well as phosphorylated KIT (pKIT) levels in R2 cells, the downstream signalling pathways, such as phosphorylated p44/42 MAPK, were not changed (Fig. 1c).

To evaluate the induction of apoptosis by TAS-116, we measured the activity of caspase- $3 / 7$ by using luminescence assays. Caspase $3 / 7$ activity increased in a dose-dependent manner after exposure to TAS-116 and was higher in GIST T1 than in GIST R8 and R9 cell lines (Fig. 1d).

Effects of HSP90 inhibitors on cellular distribution of KIT

We reported that mutated KIT in GIST cell lines accumulated on the trans-side of the Golgi apparatus ${ }^{41}$ where mutated KIT was phosphorylated on Y703 predominantly, but not on the endoplasmic reticulum (ER). ${ }^{42}$ Next, we examined the effects of the HSP90 inhibitors on KIT localisation and phosphorylation using confocal microscopy. GM130 is Golgi marker and PDI is ER marker. Treatment with TAS-116 or 17-AAG decreased Golgi-localised KIT in both IM-naïve GIST T1 and IM-resistant GIST R8 cells, but KIT remained to be co-localised with PDI (ER) in HSP90-inhibited cells (Fig. 2a, b). KIT phosphorylated on Y703 almost completely disappeared from the Golgi apparatus following the addition of HSP90 inhibitors (Fig. 2c). Similar results were obtained using GIST48/820 and GIST430/654 (Supplementary Fig. 1c, d) and GIST R9 (Supplementary Fig. 2a-c).

We used peptide-N-glycosidase F (PNGase F), which completely digest N-linked glycans, to show that the lower and upper KIT bands contained different glycans. We also treated KIT with endoglycosidase $\mathrm{H}$ (endo $\mathrm{H}$ ), which digests immature high-mannose forms, but not mature complex-glycosylated forms of KIT. We previously showed by in vitro glycosidase treatment and immunoblotting that the lower and upper KIT bands are high-mannose form (HM, endo $\mathrm{H}$-sensitive, ER and cis-side of Golgi) and complex-glycosylated form (CG, endo H-resistant, reaching trans-side of Golgi), respectively. ${ }^{41}$ TAS-116 and 17-AAG decreased both CG-KIT and HM-KIT, but the decrease in the CG form was greater than that in the HM form (Fig. 2d). As KIT is fully activated on the trans-Golgi in the CG form, these HSP90 inhibitors predominantly decrease KIT on the transGolgi compared with that on the ER and cis-Golgi.

Anti-tumour effects of TAS-116 in GIST xenograft models We evaluated the in vivo effects of TAS-116 against GIST tumours using a xenograft mouse model as shown in Fig. 3a. Both IM and TAS-116 significantly inhibited tumour growth in the GIST T1 xenograft model ( $p<0.0001$ and $<0.0001$, respectively), whereas TAS-116, but not IM, significantly suppressed tumour growth in the GIST R8 and R9 models $(p<0.0001$ and $<0.0001$, respectively) (Fig. 3b). Weight loss after TAS-116 treatment was not observed compared with that before treatment in any of the xenograft models.

We next examined the expression and phosphorylation of KIT and its downstream signalling pathways in xenograft mouse models (Fig. 3c). Not only pKIT but also its downstream signalling pathways, including AKT and p44/42 signalling, were suppressed by TAS-116 treatment. The harvested subcutaneous tumours were histologically examined (Fig. 4a). Expression of KIT was attenuated in the IM-treated GIST T1 xenograft model and in TAS-116-treated GIST T1, R8, and R9 xenografts. More importantly, Ki-67, a proliferation marker, was significantly decreased in the 
a

\begin{tabular}{cccccc}
\hline \multirow{2}{*}{ Cell line } & \multicolumn{2}{c}{ KIT mutation } & \multicolumn{3}{c}{$\mathrm{IC}_{50}(\mathrm{nM})$} \\
\cline { 2 - 5 } & Primary & Secondary & TAS-116 & 17AAG & Imatinib \\
\hline T1 & Exon11 del & & 284.0 & 15.3 & 14.87 \\
R8 & Exon11 del & Exon17 D820y & 500.4 & 41.9 & 14,530 \\
R9 & Exon11 del & Exon17 D820V & 334.9 & 18.9 & 1840 \\
R2 & Exon11 del & - & 731.8 & 82.3 & 17,000 \\
\hline
\end{tabular}

b

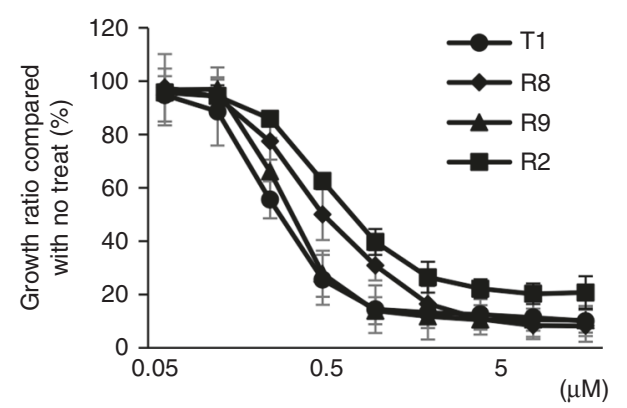

C
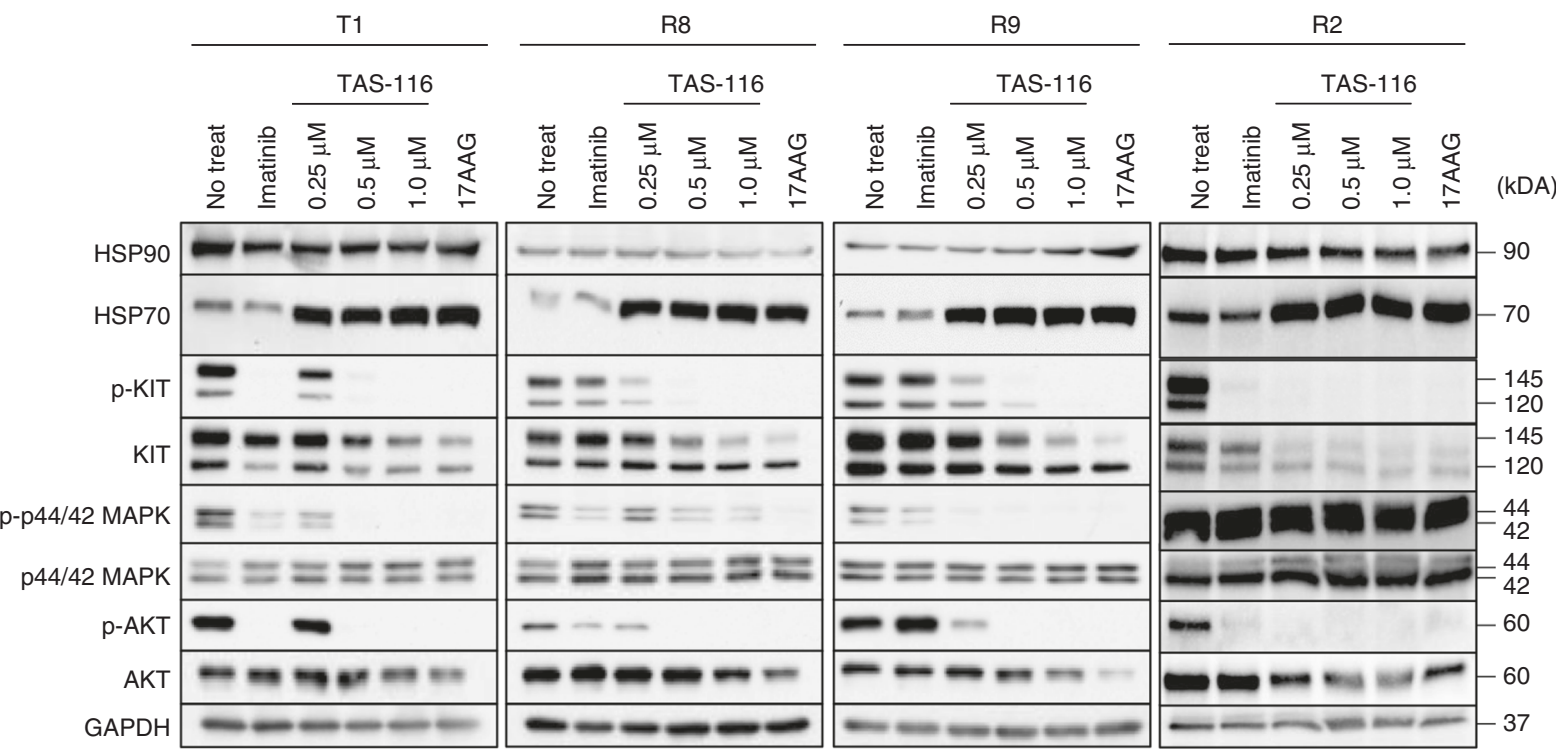

d

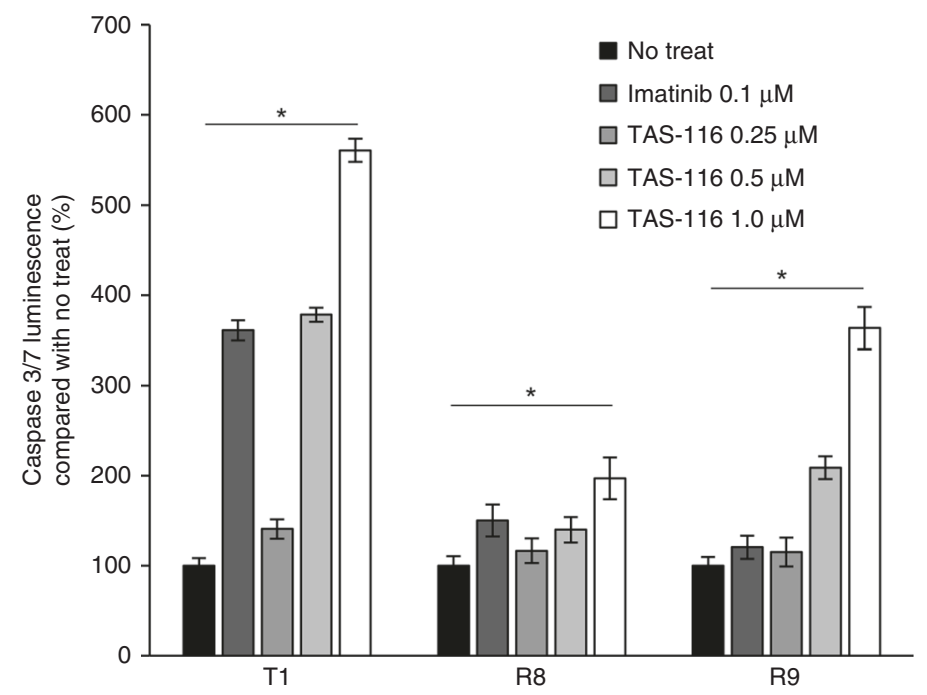

Fig. 1 Effect of HSP90 inhibition on mutant KIT signalling. a KIT gene mutation and effects of IM, TAS-116 and 17-AAG in IM-naïve and IM-resistant GIST cell lines. $\mathbf{b}$ Cell proliferation was determined by WST-8 assays at $72 \mathrm{~h}$ after incubation with TAS-116. Each value is represented as the mean \pm SD. c Western blot analysis of HSP90, HSP70, pKIT/KIT, pAKT/AKT and pERK/ERK in GIST cell lysates at $12 \mathrm{~h}$ after IM, TAS-116 and 17-AAG treatments was performed. $\mathbf{d}$ Caspase-3/7 activity was determined using luminescence assays $24 \mathrm{~h}$ after incubation with $0.1 \mu \mathrm{M}$ IM and $0.25-1.0 \mu \mathrm{M}$ TAS-116.

IM-treated GIST T1 xenograft $(p<0.0001)$ and TAS-116-treated GIST T1, R8, and R9 xenografts $(p<0.0001,=0.0005$, and $=0.0326$, respectively) (Fig. 4a, b). Consistent with the above results, TUNEL staining showed that cellular apoptosis was induced in the IMtreated GIST T1 xenograft and TAS-116-treated GIST T1, R8 and R9 xenografts (Fig. 4c).
TAS-116 suppresses the proliferation of lung cancer cell lines with EGFR mutations

To confirm the activities of TAS-116 on other tyrosine kinases, we evaluated growth inhibition by TAS-116 using several lung cancer cell lines, including EGFR-wild-type and EGFR-mutated cell lines. $I_{50}$ values of TAS-116, 17-AAG, and gefitinib were measured using 

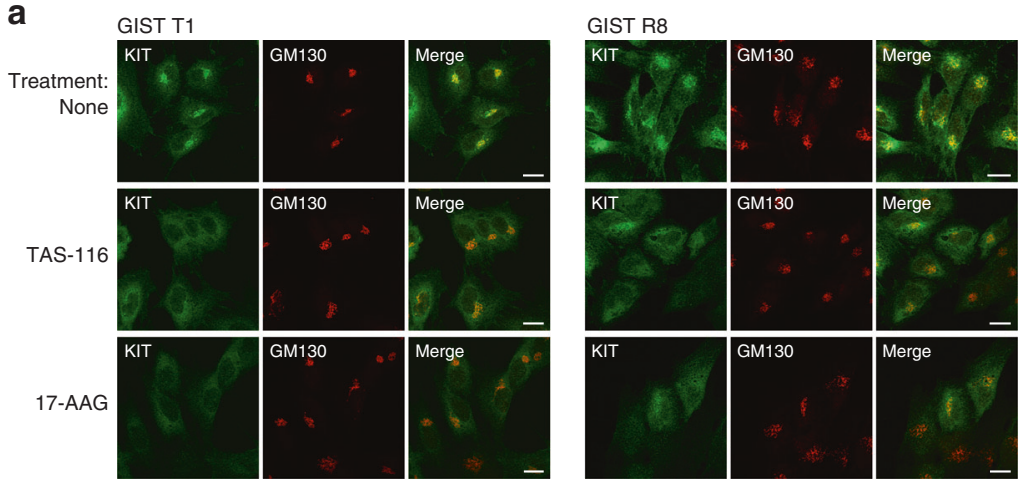

b

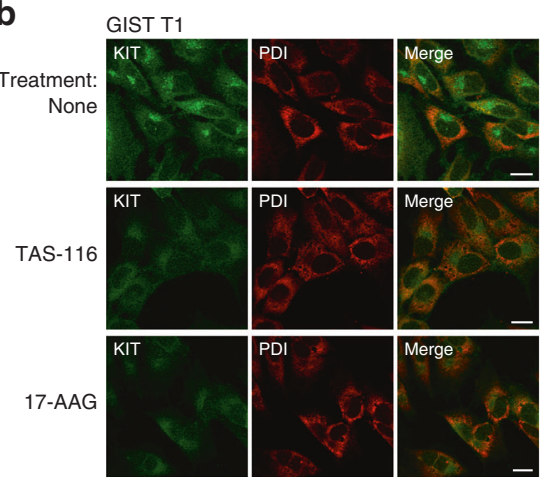

GIST R8
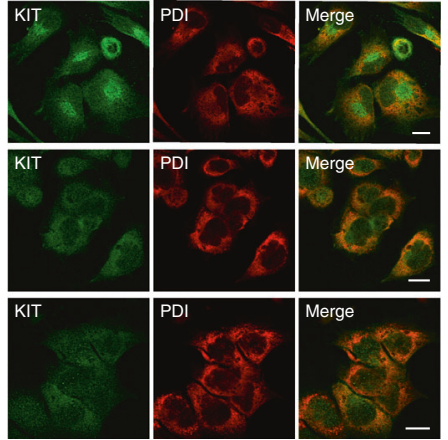

C

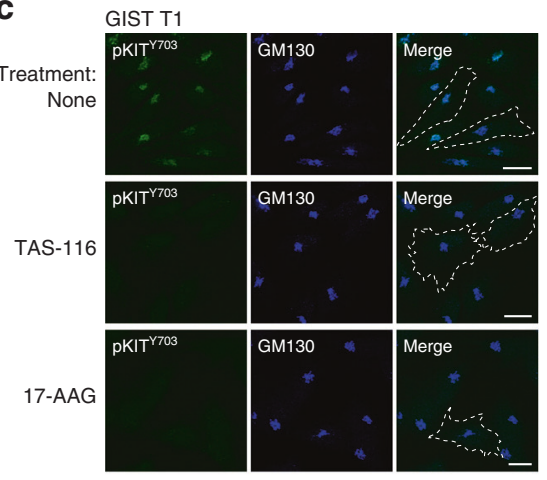

GIST R8
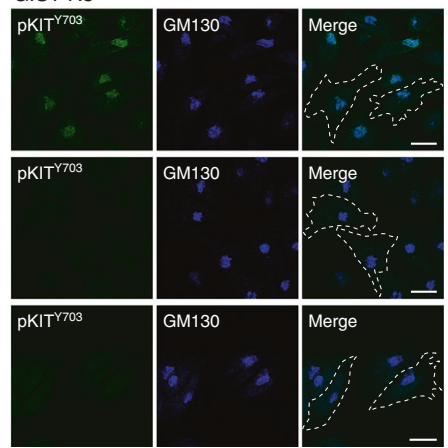

d

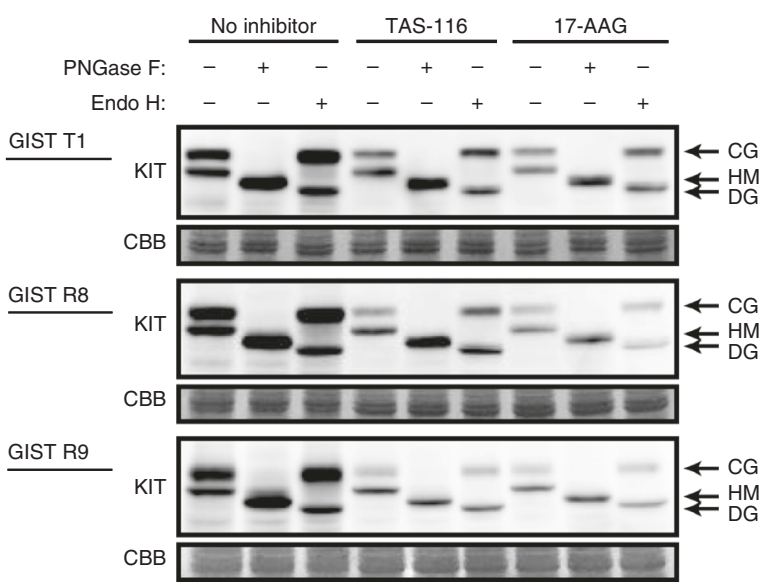

Fig. 2 Effect of HSP90 inhibition on KIT distribution and phosphorylated KIT in GIST T1 and GIST R8 cells. a-d GIST cells were treated with $1 \mu \mathrm{M}$ TAS-116 or $0.5 \mu \mathrm{M}$ 17-AAG for $12 \mathrm{~h}$. a-c The cells were stained with anti-KIT (green), anti-phosphorylated KIT $Y^{703}$ (anti-KIT $\mathrm{Y}^{703}$, green), anti-GM130 (Golgi marker, red or blue) and anti-PDI antibodies (ER marker, red). Dashed lines indicate cell borders. Bars, $20 \mu \mathrm{m}$. $\mathbf{d}$ Lysates from GIST cell lines were treated with peptide N-glycosidase F (PNGase F) or endoglycosidase H (Endo H) and then immunoblotted with anti-KIT antibody. CG complex-glycosylated form, HM high-mannose form, DG deglycosylated form. 
a
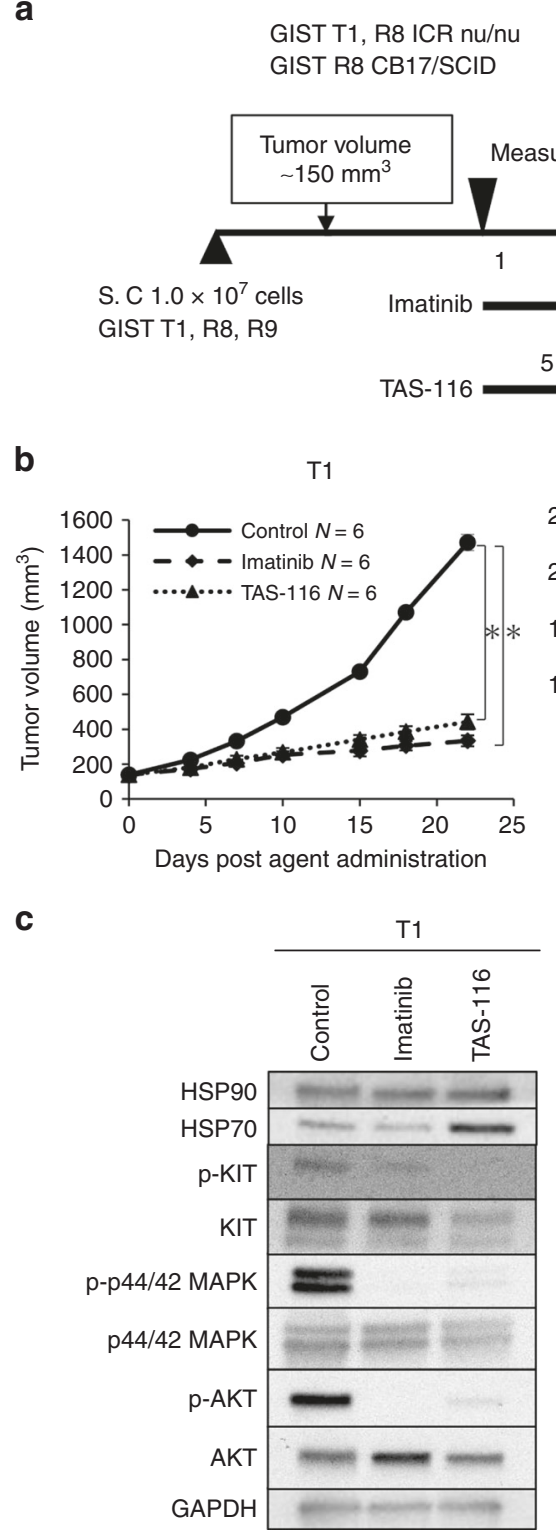

C

b

c
1. Control $0.5 \mathrm{w} / \mathrm{v} \%$ HPMC

2. Imatinib $100 \mathrm{mg} / \mathrm{kg} /$ day b.i.d.

3. TAS-116 14 mg/kg/day
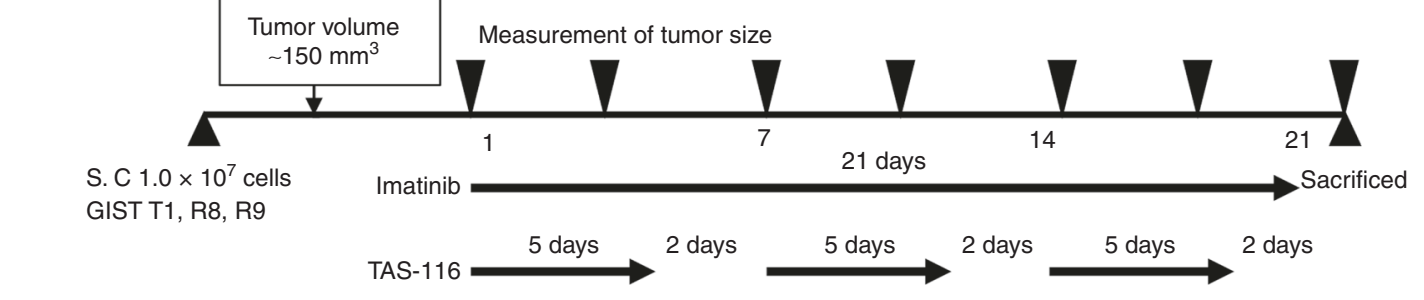

R8

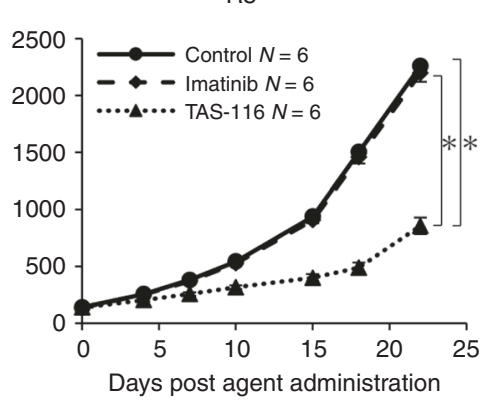

R9

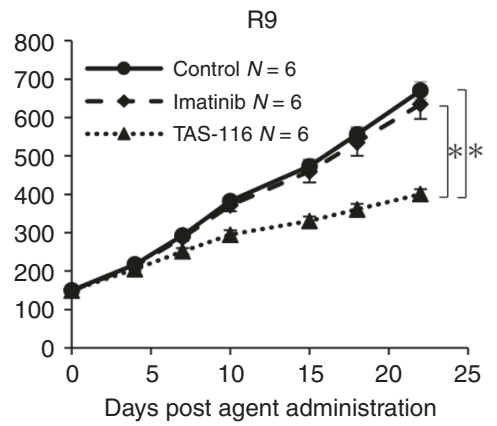

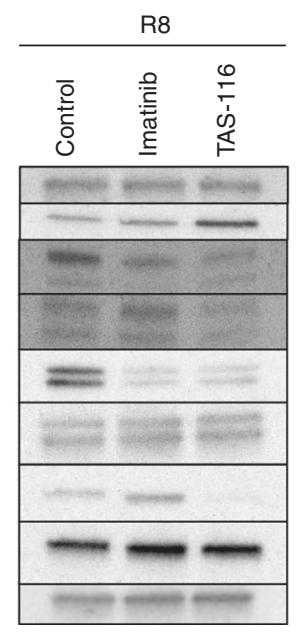

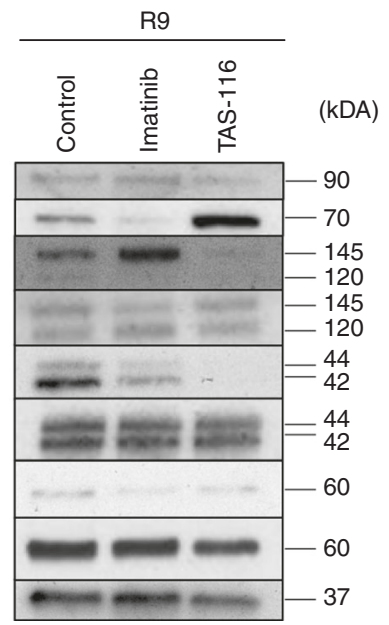

Fig. 3 TAS-116 had anti-tumour effects in xenograft mouse models. a GIST cell line xenograft mouse model; BALB/cAJcl-nu/nu mice ( 6 weeks of age) were injected with $1.0 \times 10^{7}$ cells of GIST T1 and GIST R8, whereas C.B-17/lcr-scid/scidJcl mice (7 weeks of age) were injected with $1.0 \times 10^{7}$ cells of GIST R9. When the tumour volume reached $\sim 150 \mathrm{~mm}^{3}$, xenograft tumours were treated with TAS-116 five times a week orally at $14 \mathrm{mg} / \mathrm{kg}$ and IM twice a day orally at $50 \mathrm{mg} / \mathrm{kg}$ for 3 weeks. b Tumour volumes were determined twice per week. Statistical analysis was performed using the Tukey-Kramer (HSD) test $\left({ }^{*} p<0.01\right)$. c Western blot analysis of HSP90, HSP70, pKIT/KIT, pAKT/AKT and pERK/ERK in GIST cell-derived tissues from control, IM-treated and TAS-116-treated animals.

the EGFR-wild-type cell line A549, gefitinib-naïve HCC827 (EGFR $\triangle 746-750)$ and gefitinib-resistant NCI-H1975 (EGFR L858R/T790M) (Fig. 5a). As shown in Fig. 5b, TAS-116 inhibited the proliferation of all lung cancer cell lines in a dose-dependent manner. Among the three cell lines, NCl-H1975 (EGFR L858R/T790M) appeared to be the most sensitive to TAS-116, whereas it had mild effects on the EGFR-wild-type A549 cell line. Immunoblotting showed that TAS-116 significantly induced HSP70 in NCl-H1975 cells. TAS-116 inhibited phosphorylated EGFR and its downstream signalling in $\mathrm{NCl}-\mathrm{H} 1975$ cells (Fig. $5 \mathrm{c}$ ).

Next, we examined the localisation of EGFR after treatment with TAS-116. Before the treatment, EGFR in $\mathrm{NCl}-\mathrm{H} 1975$ cells was predominantly co-localised with an endosome marker, transferrin receptor and treatment with TAS-116 or 17-AAG decreased EGFR expression in the endosomes (Fig. 5d).

\section{DISCUSSION}

Activation mutation of KIT or PDGFRA receptor tyrosine kinases is an initiating oncogenic event and it plays important roles in the proliferation of GISTs. ${ }^{43}$ This led to the development of several clinically used KIT-targeting small-molecule TKIs. ${ }^{3,4,8,9}$ HSP9O is a molecular chaperone that is crucial for many oncogenic drivers such as KIT and EGFR. ${ }^{27}$ HSP90 inhibitors, including IPI-493, IPI-504, AT13387, and AUY922, have shown inhibitory effects on GIST cell growth in preclinical studies. ${ }^{30,31,44,45}$ These inhibitors, however, have also been shown to have limited activity in clinical settings as they cause adverse events. TAS-116, an oral selective HSP90a/ $\beta$ inhibitor, showed significant anti-tumour activities without detectable ocular toxicities in a rat model. ${ }^{37}$ A Phase 1 trial of TAS-116 in patients with solid tumours demonstrated that TAS116 had an acceptable safety and preliminary anti-tumour 
a

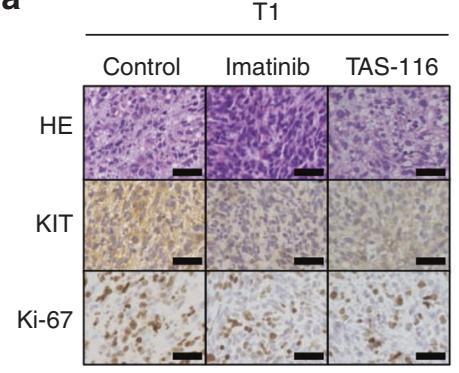

b

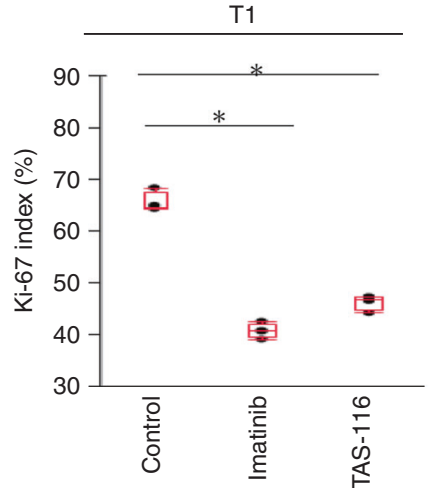

C

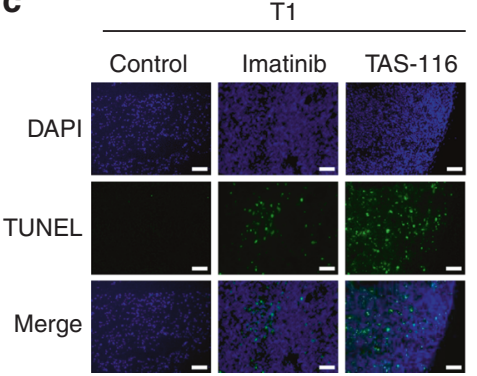

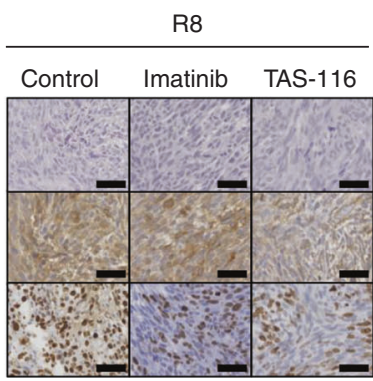

R8

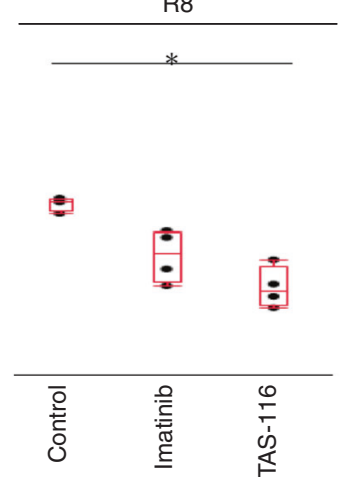

R8

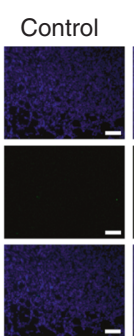

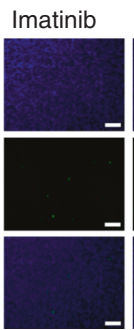

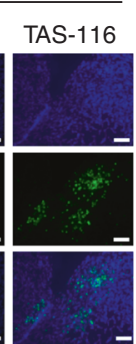

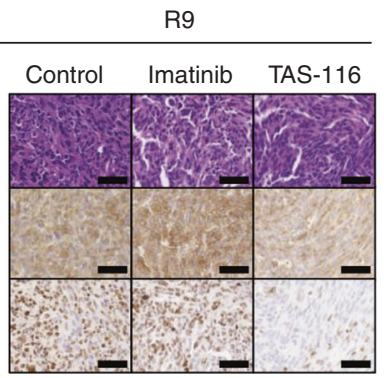
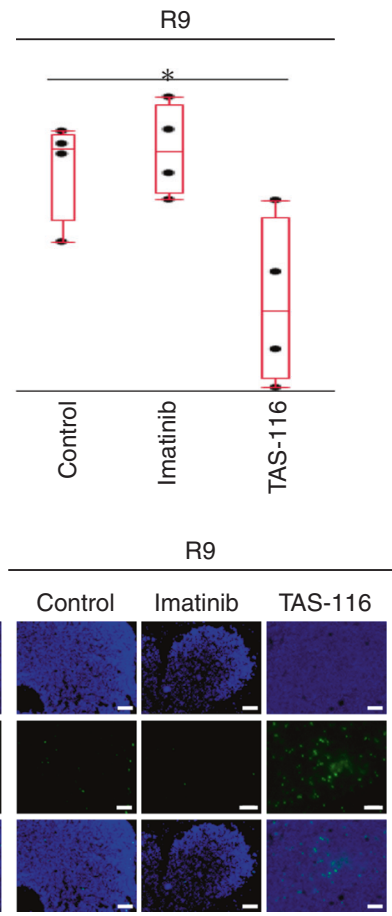

Fig. 4 Histological analysis of IM and TAS-116 in GIST cell xenograft mouse models. a Immunohistochemical analysis of KIT and Ki-67 in GIST cell xenograft mouse-derived tissue from control, IM-treated and TAS-116-treated animals. b Ki-67 staining was recorded as the ratio of positively stained cells to all tumour cells in five fields (×200 magnification). Statistical analysis was performed using the Tukey-Kramer (HSD) $t$-test $\left({ }^{*} p<0.01\right)$. c Analysis of apoptosis by TUNEL staining (blue fluorescence, DAPI staining for nuclei; green fluorescence, TUNEL-positive staining) in GIST cell xenograft mouse-derived tissue from control, IM-treated and TAS-116-treated animals. Scale bar =Black $50 \mu \mathrm{m}$, White $100 \mu \mathrm{m}$.

activity. ${ }^{46}$ The present study provides evidence that TAS-116 shows activity against GIST cell line GIST T1 and EGFR-mutated lung cancer cells.

Despite the efficacy of IM, half of the GISTs treated with IM show resistance within 2 years. This IM resistance is mainly caused by secondary mutations in the kinase domains of KIT and is accompanied by concomitant reactivation of KIT even in the presence of IM, suggesting that KIT oncoprotein remains a therapeutic target at the time of clinical progression. ${ }^{10}$ Mutated forms of the proteins are also dependent on HSP90 for their stability. ${ }^{47}$ Fumo et al. reported that HSP90 inhibition by 17-AAG destabilised KIT and led to rapid degradation of the IM-resistant KIT mutant protein with D816V mutation. ${ }^{47}$ Smyth et al. showed that AT13387 had significant anti-tumour activity in two IMresistant cell lines, which have differently resistant KIT mutations (V654A and D820A). ${ }^{30}$ Thus, these studies indicate that HSP90 is a desirable target for GISTs with various secondary mutations in KIT. HSP90 inhibitors inhibited the proliferation of both IM-naïve and IM-resistant GIST, irrespective of the type of KIT mutation. ${ }^{29}$ We have established IM-resistant GIST cell lines with secondary KIT mutations at D820Y and D820V (GIST R8 and R9), which are mutations found in IM-resistant GISTs in clinical practice. ${ }^{40}$ In this study, we showed that TAS-116 exerted inhibitory activities on both IM-naïve and KIT-dependent IM-resistant GISTs, with a decrease in pKIT and its downstream signalling activities (e.g., AKT and ERK). In contrast, TAS-116 showed less activity in the KITindependent IM-resistant GIST R2 cells. These results suggested that TAS-116 might inhibit the KIT-dependent proliferation of GISTs by the depletion of pKIT and that we may be able to predict the therapeutic effect of TAS-116 in IM-resistant GIST through the measurement of KIT activities in a clinical setting.

We previously reported that mutant KIT accumulated on the Golgi apparatus, whereas normal KIT localised to the plasma membrane. ${ }^{41}$ Both IM-naïve and IM-resistant KIT became fully autophosphorylated on the Golgi apparatus in a complexglycosylated form. ${ }^{41}$ In the present study, TAS-116 decreased fully glycosylated KIT on the trans-Golgi apparatus. There are four isoforms of HSP90 proteins and HSP90 inhibitors are reported to bind differently to these isoforms. TAS-116 was shown to have specific binding to cytosolic HSP90a/ $\beta .{ }^{37}$ We postulated that this specificity of TAS-116 might correlate with the inhibitory activities of mutant KIT. In fact, pKIT, which was located in the trans-Golgi cisternae predominantly, decreased after TAS-116 treatment (Fig. 6). 
a

\begin{tabular}{ccccc}
\hline \multirow{2}{*}{ Cell line } & EGFR mutation & \multicolumn{3}{c}{$\mathrm{IC}_{50}(\mathrm{nM})$} \\
\cline { 3 - 5 } & & TAS-116 & 17AAG & Gefitinib \\
\hline A549 & Wild type & 1874 & 83.0 & 8308 \\
HCC827 & $\Delta 746-750$ & 916 & 51.6 & 37.0 \\
NCl-H1975 & L858R, T790M & 229 & 65.8 & 9448 \\
\hline
\end{tabular}

b

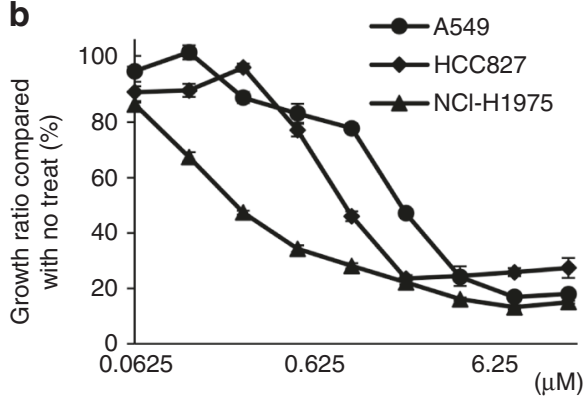

C

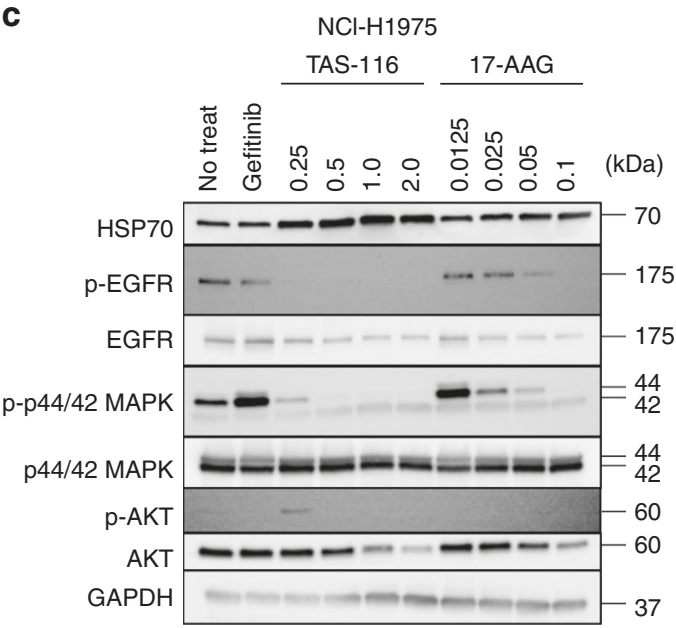

d

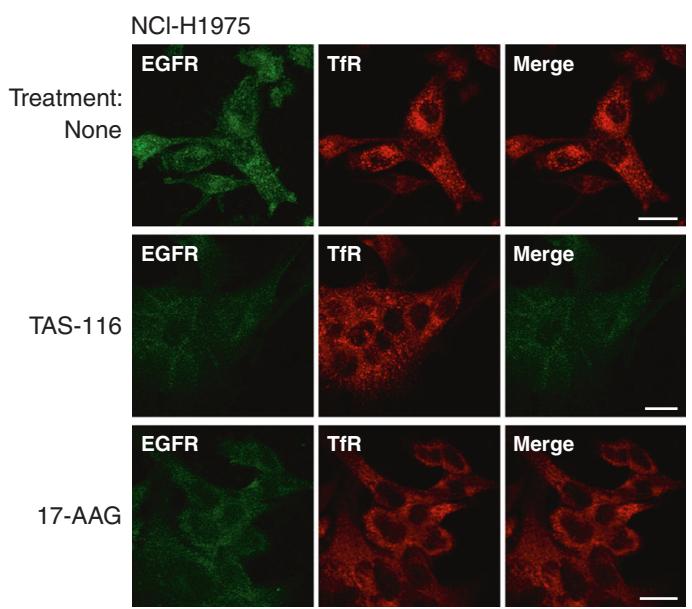

Fig. 5 Effects of HSP90 inhibition on mutant EGFR signalling. a EGFR gene mutation and effects of gefitinib, TAS-116 and 17-AAG in gefitinib-naïve and gefitinib-resistant lung cancer cell lines. b Cell proliferation was determined by WST-8 assays at $72 \mathrm{~h}$ after incubation with TAS-116. Each value is represented as the mean \pm SD. c Western blot analysis of HSP70, pEGFR/EGFR, pAKT/AKT and pERK/ERK in NCI-H1975 cell lysates at $24 \mathrm{~h}$ after gefitinib, TAS-116 or 17-AAG treatment was performed. d NCI-H1975 cells were treated with $2 \mu \mathrm{M}$ TAS-116 or $0.1 \mu \mathrm{M}$ 17-AAG for $24 \mathrm{~h}$. Cells were stained with anti-EGFR (green), and anti-TfR antibodies (endosome marker, red). Bars, $20 \mu \mathrm{m}$.

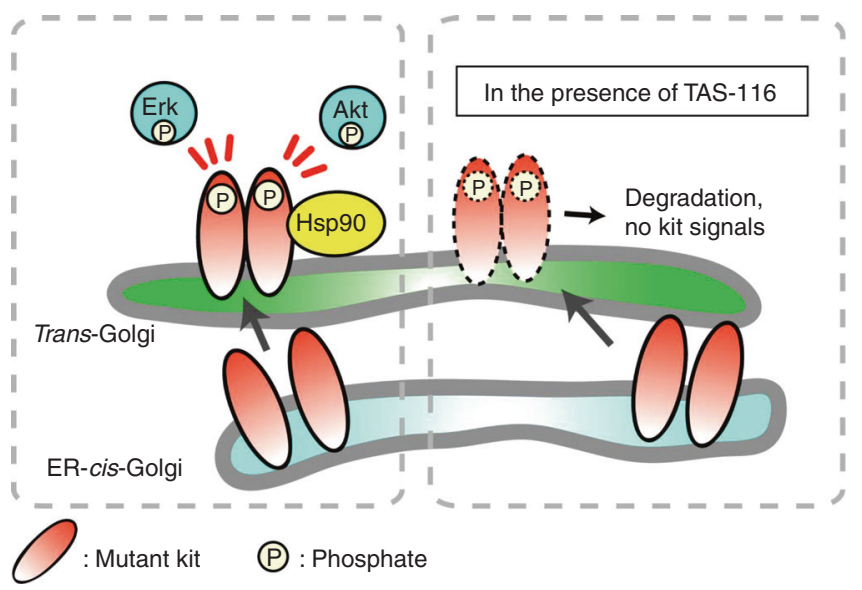

Fig. 6 Model of mutant KIT signalling on intracellular compartments in GISTs. Newly synthesised mutant KIT traffics from the ER to the Golgi complex. After reaching the Golgi complex, mutant KIT can activate the PI3K-AKT pathway and ERK. Phosphorylated KIT in the Golgi complex requires HSP90 for stability. TAS-116 mediates the degradation of phosphorylated KIT.

We also showed that TAS-116 was effective against EGFRmutated lung cancer by decreasing EGFR in endosomes. TAS-116 may be effective against tumours resistant to TKIs due to secondary mutations, such as in GISTs or EGFR-mutated lung cancer. In clinical trials, HSP90 inhibitors were reported to be effective against cancers with driver mutation products that are clients of HSP90, such as KIT, EGFR, ALK, HER2 and BRAF. ${ }^{15}$ Taken together, TAS-116 may be potentially active against TKI-resistant cancers with driver mutations, of which products are clients of $\mathrm{HSP} 90 \mathrm{a} / \beta$.

There are several limitations to this study. First, we examined only three GIST cell lines and two EGFR-mutated lung cancer cell lines. However, GIST cell lines are rare; especially IM-resistant GIST cell lines with secondary mutations established are quite unique. Second, TAS-116 decreased KIT protein levels on the Golgi apparatus; however, the effects of TAS-116 on the protein structure and mechanism of KIT degradation are still unknown; further experiments to elucidate how KIT protein is degraded on the Golgi apparatus by HSP90 inhibition are required.

Finally, we showed that TAS-116 has significant anti-tumour effects against both IM-naïve and IM-resistant xenograft models and is safe. The highly selective HSP90 $\alpha / \beta$ inhibitor TAS-116 did not inhibit the interaction between GRP94 and LRP6, which may have resulted in decreased GRP94-related gastrointestinal toxicity. ${ }^{37}$ A Phase 2 clinical study has shown that TAS-116 is welltolerated and has significant clinical benefits in patients with metastatic or unresectable GISTs refractory to standard therapies as a $\geq 4$ th-line treatment. ${ }^{48}$ Furthermore, a confirmatory trial is ongoing for its pharmaceutical approval.

In conclusion, our results showed that TAS-116 effectively inhibited the proliferation of IM-naïve and IM-resistant GIST cells and reduced the growth of GIST tumours in a xenograft mouse model. It was also effective against gefitinib-naïve and gefitinibresistant EGFR-mutated lung cancer. These anti-tumour effects appear to be mediated by the downregulation of pKIT in the Golgi apparatus or EGFR in the endosomes. We propose that TAS-116 
may be a promising drug to overcome TKI-resistant GISTs and lung cancer.

\section{ACKNOWLEDGEMENTS}

TAS-116 was provided by Taiho Pharmaceutical Co. Ltd. We thank Editage (www. editage.jp) for English language editing.

\section{AUTHOR CONTRIBUTIONS}

Conception and design: Y.S., T.T. and T.N.; Development of methodology: Y.S., T.T., Y.O., S.O., S.S., M.F., T.O., T.N., T.S., M.K., T.I., S.H. and T.N.; Acquisition of data: Y.S, T.T., Y.O., F.N. and S.S., M.K., T.I.; Analysis and interpretation of data: Y.S. T.T., Y.O., T.N., S.S., K.T., Y.M., T.M., Y.K., M.Y., K.N., T.N., M.M. and Y.D.; Writing, review and/or revision of the manuscript: Y.S., T.T., Y.O., S.S., T.N., M.M. and Y.D.; Administrative, technical or material support: S.S. and Y.O.; Study supervision: T.N.

\section{ADDITIONAL INFORMATION}

Ethical approval and consent to participate The Osaka University Animal Experiments Committee had given ethical approval for the animal studies (ethical approval number: 27-061-002).

Data availability All data generated or analysed during this study are included in this published article and its supplementary information files.

Competing interests S.O. and F.N. are employees of Taiho Pharmaceutical Co. Ltd. The other authors declare no potential Competing interests.

Funding information This study was partially supported by a Grant-in-Aid for Scientific Research (C) and Taiho.

Supplementary information is available for this paper at https://doi.org/10.1038/ s41416-019-0688-y.

Note This work is published under the standard license to publish agreement. After 12 months the work will become freely available and the license terms will switch to a Creative Commons Attribution 4.0 International (CC BY 4.0).

Publisher's note Springer Nature remains neutral with regard to jurisdictional claims in published maps and institutional affiliations.

\section{REFERENCES}

1. DeMatteo, R. P., Lewis, J. J., Leung, D., Mudan, S. S., Woodruff, J. M. \& Brennan, M. F. Two hundred gastrointestinal stromal tumors: recurrence patterns and prognostic factors for survival. Ann. Surg. 231, 51-58 (2000).

2. Hirota, S., Isozaki, K., Moriyama, Y., Hashimoto, K., Nishida, T., Ishiguro, S. et al. Gain-of-function mutations of c-kit in human gastrointestinal stromal tumors. Science 279, 577-580 (1998).

3. Corless, C. L., Fletcher, J. A. \& Heinrich, M. C. Biology of gastrointestinal stromal tumors. J. Clin. Oncol. 22, 3813-3825 (2004).

4. Demetri, G. D., von Mehren, M., Antonescu, C. R., DeMatteo, R. P., Ganjoo, K. N., Maki, R. G. et al. NCCN task force report: update on the management of patients with gastrointestinal stromal tumors. J. Natl Compr. Canc. Netw. 8(Suppl 2), 1-41 (2010)

5. Debiec-Rychter, M., Dumez, H., Judson, I., Wasag, B., Verweij, J., Brown, M. et al. Use of c-KIT/ PDGFRA mutational analysis to predict the clinical response to imatinib in patients with advanced gastrointestinal stromal tumours entered on phase I and II studies of the EORTC Soft Tissue and Bone Sarcoma Group. Eur. J. Cancer 40, 689-695 (2004).

6. Heinrich, M. C., Corless, C. L., Demetri, G. D., Blanke, C. D., von Mehren, M., Joensuu, $\mathrm{H}$. et al. Kinase mutations and imatinib response in patients with metastatic gastrointestinal stromal tumor. J. Clin. Oncol. 21, 4342-4349 (2003).

7. Gramza, A. W., Corless, C. L. \& Heinrich, M. C. Resistance to tyrosine kinase inhibitors in gastrointestinal stromal tumors. Clin. Cancer Res. 15, 7510-7518 (2009).

8. Demetri, G. D., van Oosterom, A. T., Garrett, C. R., Blackstein, M. E., Shah, M. H., Verweij, J. et al. Efficacy and safety of sunitinib in patients with advanced gastrointestinal stromal tumour after failure of imatinib: a randomised controlled trial. Lancet 368, 1329-1338 (2006).

9. Demetri, G. D., Reichardt, P., Kang, Y. K., Blay, J. Y., Rutkowski, P., Gelderblom, H. et al. Efficacy and safety of regorafenib for advanced gastrointestinal stromal tumours after failure of imatinib and sunitinib (GRID): an international, multicentre, randomised, placebo-controlled, phase 3 trial. Lancet 381, 295-302 (2013).

10. Hsueh, Y. S., Lin, C. L., Chiang, N. J., Yen, C. C., Li, C. F., Shan, Y. S. et al. Selecting tyrosine kinase inhibitors for gastrointestinal stromal tumor with secondary KIT activation-loop domain mutations. PLoS ONE 8, E65762 (2013).

11. Wardelmann, E., Thomas, N., Merkelbach-Bruse, S., Pauls, K., Speidel, N., Büttner, R. et al. Acquired resistance to imatinib in gastrointestinal stromal tumours caused by multiple KIT mutations. Lancet Oncol. 6, 249-251 (2005).

12. Shah, N. P., Nicoll, J. M., Nagar, B., Gorre, M. E., Paquette, R. L., Kuriyan, J. et al. Multiple $B C R-A B L$ kinase domain mutations confer polyclonal resistance to the tyrosine kinase inhibitor imatinib (STI571) in chronic phase and blast crisis chronic myeloid leukemia. Cancer Cell 2, 117-125 (2002).

13. Leigl, B., Kepten, I., Le, C., Zhu, M., Demetri, G. D., Heinrich, M. C. et al. Heterogeneity of kinase resistance mechanisms in GIST. J. Pathol. 216, 64-74 (2008).

14. Kobayashi, Y., Azuma, K., Nagai, H., Kim, Y. H., Togashi, Y., Sesumi, Y. et al. Characterization of EGFR T790M, L792F, and C797S mutations as mechanisms of acquired resistance to afatinib in lung cancer. Mol. Cancer Ther. 16, 357-364 (2017).

15. Garcia-Carbonero, R., Carnero, A. \& Paz-Ares, L. Inhibition of HSP90 molecular chaperones: moving into the clinic. Lancet Oncol. 14, E358-E369 (2013).

16. Isaacs, J. S., Xu, W. \& Neckers, L. Heat shock protein 90 as a molecular target for cancer therapeutics. Cancer Cell 3, 213-217 (2003).

17. Workman, P., Burrows, F., Neckers, L. \& Rosen, N. Drugging the cancer chaperone HSP90: combinatorial therapeutic exploitation of oncogene addiction and tumor stress. Ann. N. Y. Acad. Sci. 1113, 202-216 (2007).

18. Pearl, L. H., Prodromou, C. \& Workman, P. The Hsp90 molecular chaperone: an open and shut case for treatment. Biochem. J. 410, 439-453 (2008).

19. Banerji, U. Heat shock protein 90 as a drug target: some like it hot. Clin. Cancer Res. 15, 9-14 (2009)

20. Kamal, A., Boehm, M. F. \& Burrows, F. J. Therapeutic and diagnostic implications of Hsp90 activation. Trends Mol. Med. 10, 283-290 (2004).

21. Solit, D. B., Scher, H. I. \& Rosen, N. Hsp90 as a therapeutic target in prostate cancer. Semin. Oncol. 30, 709-716 (2003).

22. Munster, P. N., Basso, A., Solit, D., Norton, L. \& Rosen, N. Modulation of Hsp90 function by ansamycins sensitises breast cancer cells to chemotherapy-induced apoptosis in an RB- and schedule-dependent manner. Clin. Cancer Res. 7, 2228-2236 (2001).

23. Blagosklonny, M. V., Fojo, T., Bhalla, K. N., Kim, J. S., Trepel, J. B., Figg, W. D. et al. The Hsp90 inhibitor geldanamycin selectively sensitises Bcr-Ablexpressing leukemia cells to cytotoxic chemotherapy. Leukemia. 15, 1537-1543 (2001).

24. Munster, P. N., Srethapakdi, M., Moasser, M. M. \& Rosen, N. Inhibition of heat shock protein 90 function by ansamycins causes the morphological and functional differentiation of breast cancer cells. Cancer Res. 61, 2945-2952 (2001).

25. Biamonte, M. A., Van de Water, R., Arndt, J. W., Scannevin, R. H., Perret, D. \& Lee, W. C. Heat shock protein 90: inhibitors in clinical trials. J. Med. Chem. 53, 3-17 (2010).

26. Hornick, J. L. \& Fletcher, C. D. The role of KIT in the management of patients with gastrointestinal stromal tumors. Hum. Pathol. 38, 679-687 (2007).

27. Csermely, P., Schnaider, T., Soti, C., Prohaszka, Z. \& Nardai, G. The 90-kDa molecular chaperone family: structure, function, and clinical applications. A comprehensive review. Pharmacol. Ther. 79, 129-168 (1998).

28. Solit, D. B. \& Rosen, N. Hsp90: a novel target for cancer therapy. Curr. Top. Med. Chem. 6, 1205-1214 (2006).

29. Bauer, S., Yu, L. K., Demetri, G. D. \& Fletcher, J. A. Heat shock protein 90 inhibition in imatinib-resistant gastrointestinal stromal tumor. Cancer Res. 66, 9153-9161 (2006).

30. Smyth, T., Van Looy, T., Curry, J. E., Rodriguez-Lopez, A. M., Wozniak, A., Zhu, M. et al. The HSP90 inhibitor, AT13387, is effective against imatinib-sensitive and -resistant gastrointestinal stromal tumor models. Mol. Cancer Ther. 11, 1799-1808 (2012).

31. Floris, G., Debiec-Rychter, M., Wozniak, A., Stefan, C., Normant, E., Faa, G. et al. The heat shock protein 90 inhibitor IPI-504 induces KIT degradation, tumor shrinkage, and cell proliferation arrest in xenograft models of gastrointestinal stromal tumors. Mol. Cancer Ther. 10, 1897-1908 (2011).

32. Jhaveri, K., Taldone, T., Modi, S. \& Chiosis, G. Advances in the clinical development of heat shock protein 90 (Hsp90) inhibitors in cancers. Biochim. Biophys. Acta. 1823, 742-755 (2012).

33. Saif, M. W., Takimoto, C., Mita, M., Banerji, U., Lamanna, N., Castro, J. et al. A phase 1, dose-escalation, pharmacokinetic and pharmacodynamic study of BllB021 administered orally in patients with advanced solid tumors. Clin. Cancer Res. 20, 445-455 (2014).

34. Goldman, J. W., Raju, R. N., Gordon, G. A., El-Hariry, I., Teofilivici, F., Vukovic, V. M. et al. A first in human, safety, pharmacokinetics, and clinical activity phase I study of once weekly administration of the Hsp90 inhibitor ganetespib (STA-9090) in patients with solid malignancies. BMC Cancer. 13, 152 (2013). 
TAS-116 inhibits oncogenic KIT signalling on the Golgi in both...

Y Saito et al.

35. Rajan, A., Kelly, R. J., Trepel, J. B., Kim, Y. S., Alarcon, S. V., Kummar, S. et al. A phase I study of PF-04929113 (SNX-5422), an orally bioavailable heat shock protein 90 inhibitor, in patients with refractory solid tumor malignancies and lymphomas. Clin. Cancer Res. 17, 6831-6839 (2011).

36. Sessa, C., Shapiro, G. I., Bhalla, K. N., Britten, C., Jacks, K. S., Mita, M. et al. First-inhuman phase I dose-escalation study of the HSP90 inhibitor AUY922 in patients with advanced solid tumors. Clin. Cancer Res. 19, 3671-3680 (2013).

37. Ohkubo, S., Kodama, Y., Muraoka, H., Hitotsumachi, H., Yoshimura, C., Kitade, M. et al. TAS-116, a highly selective inhibitor of heat shock protein $90 \mathrm{a}$ and $\beta$, demonstrates potent antitumor activity and minimal ocular toxicity in preclinical models. Mol. Cancer Ther. 14, 14-22 (2015).

38. Yokoyama, T., Enomoto, T., Serada, S., Morimoto, A., Matsuzaki, S., Ueda, Y. et al. Plasma membrane proteomics identifies bone marrow stromal antigen 2 as a potential therapeutic target in endometrial cancer. Int. J. Cancer. 132, 472-484 (2013).

39. Taguchi, T., Sonobe, H., Toyonaga, S., Yamasaki, I., Shuin, T., Takano, A. et al. Conventional and molecular cytogenetic characterization of a new human cell line, GIST-T1, established from gastrointestinal stromal tumor. Lab. Invest. 82, 663-665 (2002).

40. Takahashi, T., Elzawahry, A., Mimaki, S., Furukawa, E., Nakatsuka, R., Nakamura, H et al. Genomic and transcriptomic analysis of imatinib resistance in gastrointestinal stromal tumors. Genes Chromosomes Cancer 56, 303-313 (2017).

41. Obata, Y., Horikawa, K., Takahashi, T., Akieda, Y., Tsujimoto, M., Fletcher, J. A. et al. Oncogenic signaling by Kit tyrosine kinase occurs selectively on the Golgi apparatus in gastrointestinal stromal tumors. Oncogene. 36, 3661-3672 (2017).
42. Obata, Y., Horikawa, K., Shiina, I., Takahashi, T., Murata, T., Tasaki, Y. et al. Oncogenic Kit signalling on the Golgi is suppressed by blocking secretory trafficking with M-COPA in gastrointestinal stromal tumours. Cancer Lett. 415, 1-10 (2018).

43. Corless, C. L., McGreevey, L., Haley, A., Town, A. \& Heinrich, M. C. KIT mutations are common in incidental gastrointestinal stromal tumors one centimeter or less in size. Am. J. Pathol. 160, 1567-1572 (2002).

44. Floris, G., Sciot, R., Wozniak, A., Van Looy, T., Wellens, J., Faa, G. et al. The Novel HSP90 inhibitor, IPI-493, is highly effective in human gastrostrointestinal stromal tumor xenografts carrying heterogeneous KIT mutations. Clin. Cancer Res. 17, 5604-5614 (2011).

45. Hsueh, Y. S., Yen, C. C., Shih, N. Y., Chiang, N. J., Li, C. F. \& Chen, L. T. Autophagy is involved in endogenous and NVP-AUY922-induced KIT degradation in gastrointestinal stromal tumors. Autophagy. 9, 220-233 (2013).

46. Yanagitani, N., Horiike, A., Kitazono, S., Ohyanagi, F., Kondo, S., Shimomura, A et al. First-in-human phase I study of an oral HSP90 inhibitor, TAS-116, in advanced solid tumors. J. Clin. Oncol. 35(Suppl 15), abstract 2546 (2017).

47. Fumo, G., Akin, C., Metcalfe, D. D. \& Neckers, L. 17-Allylamino-17demethoxygeldanamycin (17-AAG) is effective in down-regulating mutated constitutively activated KIT protein in human mast cells. Blood 103, 1078-1084 (2004).

48. Doi, T., Kurokawa, Y., Sawaki, A., Komatsu, Y., Ozaka, M., Takahashi, T. et al. Phase II study of TAS-116, an oral inhibitor of heat shock protein 90 (HSP90), in metastatic or unresectable gastrointestinal stromal tumor refractory to imatinib, sunitinib and regorafenib Eur J Cancer. 121 29-39 (2019). 